\title{
O que se diz sobre a escola pública de horário integral
}

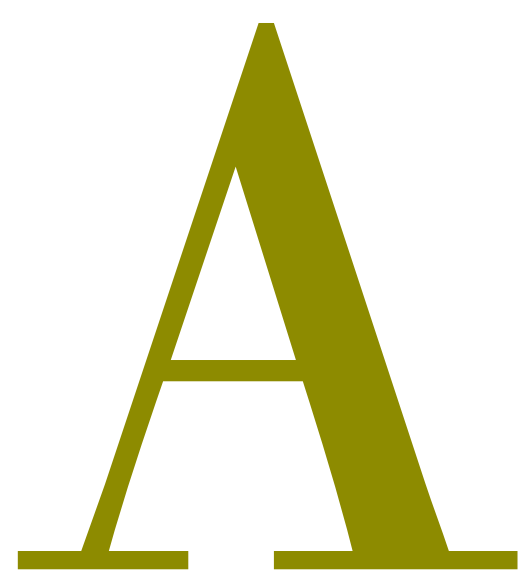

produção escrita sobre a escola pública de horário integral pode ser vista em dois ciclos delimitados no tempo. As críticas desfavoráveis, concentradas essencialmente no período de 1987 a 1991, baseiam-se nos dados do I Programa Especial de Educação - PEE. As apreciações favoráveis começaram a surgir em 1990 e tiveram continuidade com dados do II PEE. Os críticos divulgaram suas idéias em revistas ou editoras de maior circulação que os defensores da escola de horário integral, cujas teses ou dissertações permaneceram, praticamente, restritas às universidades.

Antes de relacionar os aspectos positivos e negativos apontados por diversos autores a respeito do projeto dos CIEPs, é esclarecedor ilustrar o cenário da época. No artigo "A escola de $1^{\circ}$ grau em tempo integral: as lições da prática”, Zaia Brandão (1989) expõe sua relutância em participar do seminário promovido pela Fundação Carlos Chagas, em 1987, tal o clima "emocional" em relação ao PEE. Depois de relatar os encontros que teve com Darcy Ribeiro, que deram origem ao seu criticismo em relação aos CIEPs, reconhece que sua reação reflete preconceitos e vícios da academia. Afirma que o impacto nacional causado pelo programa dos CIEPs colocou em discussão não as escolas, e sim a disputa político-partidária representada por Leonel Brizola, Darcy Ribeiro e Oscar Niemeyer.

A autora, a despeito de reconhecer o boicote da imprensa ao Governo Brizola, considera que as críticas veiculadas expressam a polêmica levantada pelos CIEPs:

- constituição de uma rede paralela;

- escola como outdoor;

* Lúcia Velloso Maurício é Doutora em Educação pela Universidade Federal do Rio de Janeiro (UFRJ); Professora adjunta do mestrado em Educação da Universidade Estácio de Sá; Professora adjunta da Faculdade de Formação de Professores da Universidade do Estado do Rio de Janeiro (UERJ); Consultora da Fundação Darcy Ribeiro. 
- prioridade ao tempo integral, em detrimento do terceiro turno;

- ausência de proposta pedagógica;

- custo muito alto.

Zaia Brandão conclui que o CIEP representou ousadia para romper com a tradição, apesar das mazelas enfrentadas por causa da urgência da implantação. O Programa deixou questões para reflexão:

- crianças que completam a renda familiar;

- espaço/tempo ampliado atende à demanda das camadas populares;

- estigma desenvolvido pelos próprios idealizadores dos CIEPs.

Destacou como positivo:

- prédio e horário novos trazem motivação;

- o projeto de horário integral criou condições para formação em serviço;

- a figura das professoras-orientadoras; e

- a proposta da língua como eixo interdisciplinar.

\section{As críticas desfavoráveis}

\section{Populismo}

Entre as críticas desfavoráveis, era lugar comum abordar o populismo. Os argumentos (Mignot, 1988) focalizavam ausência de transparência em relação a custos, a critério de localização, a número de escolas concluídas e de alunos atendidos. A tese de Leal (1991) sistematizou a literatura sobre clientelismo, definindo-o como a distribuição de benefícios oriundos de recursos públicos, efetivada por indivíduos ou grupos no poder, para atender interesses particulares em troca de lealdade, apoio político e até vantagens econômicas, resultando em alto grau de ineficiência social. 0 estudo mapeou as práticas clientelistas na educação de $1^{\circ}$ e $2^{\circ}$ Graus no Brasil, por meio de aquisição e distribuição de livros didáticos, merenda e bolsas de estudo; construção de escolas; recrutamento e lotação de professores.

A questão da construção dos CIEPs mereceu destaque porque revelou a contradição entre o planejamento do PEE e seu resultado. Segundo a autora, o diagnóstico que deu origem ao Programa foi coerente com o problema educacional quando criticou o funcionamento e a estrutura da escola pública e enfatizou a necessidade de se repensarem aspectos do ensino-aprendizagem. Entretanto, a implantação afastou-se do diagnóstico na medida em que se concentrou na construção dos CIEPs. Cunha (1991) considerou que a localização inadequada dos escolões não eliminou o terceiro turno, que a pressa nas construções para fins eleitorais deixou vazamentos e que obras monumentais como o CIEP têm objetivo de aumentar os valores simbólicos dos governantes e engordar as "caixinhas".

\section{Inviabilidade}

O segundo tema das críticas, a inviabilidade de universalização da escola de horário integral, foi primeiramente abordado por Paro et al. (1988b e 1988c) como resultado de estudo promovido pela Fundação Carlos Chagas, alegando que a simples extensão da escolaridade diária não garantia o funcionamento ótimo da escola. Consideram que o pequeno tempo de permanência do aluno na escola é um grave problema, mas há outros do mesmo porte: a superlotação das salas de aula, que pode ser solucionada sem extensão da escolaridade; o salário do professor, que tem que trabalhar em vários lugares; a precariedade de instalações; a escassez de material didático etc. Para os autores, a proposta de horário integral ignorava que o mínimo estabelecido por lei de quatro horas diárias ainda estava para ser atingido. Assim, o custo muito alto com incerteza de benefício inviabilizava a universalização da escola de horário integral no Ensino Fundamental.

\section{Custo}

Oliveira (1991) distinguiu dois tipos de críticas ao custo dos CIEPs: de um lado, as que discordavam da oportunidade de implantar uma escola como essa; de outro, as que incidiam sobre a análise dos gastos dessa implantação. Rebate a impossibilidade de universalização do atendimento em tempo integral quando não se garantia ainda ensino de boa qualidade em tempo parcial, alegando que a escola unitária tem sido confundida com uniformidade de atendimento. No mesmo sentido, Coelho (1996) afirmou que qualidade emancipatória a ser desenvolvida no ensino público fundamental requer democracia que se lê, minimamente, como acesso e permanência na escola, mesmo que seja necessário facultar condições desiguais para que as crianças das classes desprivilegiadas possam se tornar iguais. Concluiu que a extensão da quantidade de horas na escola é con- 


\section{[...] na escola real, a socialização tem consistido de práticas autoritárias que recalcam a cultura do dominado, até que essas crianças sejam expulsas da escola sem aprender o mínimo necessário.}

dição para desenvolver a qualidade emancipatória, inserindo conteúdo político na qualidade de ensino.

Um artigo específico sobre o tema (Costa, 1991) comparou os custos de uma escola convencional e de um CIEP de $1^{\underline{a}}$ à $4^{\underline{a}}$ série, assim como os custos de outro par de $5^{\underline{a}}$ à $8^{a}$ série. A autora dividiu os custos em pessoal, material e capital (prédio). Exemplificando com os dados do primeiro segmento, o CIEP apresentou custo aluno/ano três vezes maior que o da escola convencional nos aspectos pessoal e material, e duas vezes maior no tocante ao prédio. Concluiu que as despesas assistenciais não eram relevantes. Como tanto no CIEP quanto na outra escola, a maior parte do custo aluno (60\%) está na despesa com pessoal, este se mostrou realmente o fator significativo. Ou seja, o CIEP, com sua capacidade completa, apresentaria resultado diferente, pois a comparação foi feita entre taxas, e não entre valores absolutos.

\section{Função da escola}

A quarta vertente da crítica discutiu a função da escola. Paro et al. (1988 a) reafirmaram a função de instrução da escola, sem desconhecer a de socialização, mais importante para as crianças das camadas populares que não contam com alternativas de lazer em ambientes coletivos diversificados. Entretanto, consideraram que, na escola real, a instrução tem sido reduzida a mínimos insignificantes e a socialização tem consistido de práticas autoritárias que recalcam a cultura do dominado, até que essas crianças sejam expulsas da escola sem aprender o mínimo necessário.

O que se divisava por trás do caráter formador da escola voltada para as classes trabalhadoras era a concepção de pobreza como problema moral, que devia ser eliminado por meio da educação integral. Argumentaram que as propostas de horário integral daquele momento se apresentavam como alternativas à FEBEM, que obteve êxito na segregação e fracassou na "ressocialização das crianças das classes populares.
Arroyo (1988), ao discorrer sobre as funções que as escolas de tempo integral assumiram ao longo da história, destacou seu caráter de instituição total, em que se valorizava mais a socialização do que a instrução. Alertou para a percepção negativa da pobreza que essas instituições, destinadas a salvar os filhos dos trabalhadores pobres, têm, mostrando quão violenta pode ser a relação pedagógica. A escola pública de horário integral poderia servir para o fortalecimento político cultural dos trabaIhadores. Cavalieri (1996) considera que há, atualmente, ampliação das funções da escola por modificação da natureza da instrução escolar. 0 tempo de permanência diária passou a ser condição para que a escola possa desempenhar essas novas atribuições.

A comparação feita por Leonardos em três pesquisas (1990, 1991 b e 1992), entre um CIEP e uma escola convencional situados na mesma comunidade, Cidade de Deus, ambos de $1^{\text {a à }} 4^{\text {a }}$ série, trouxe informações novas para a discussão sobre a função da escola de horário integral. 0 estudo, que considerou pensamento crítico como capacidade de avaliar uma idéia, tomar uma posição e argumentar, investigou a fala, a leitura e a escrita em turmas de $4^{\text {a }}$ série.

O levantamento socioeconômico indicou que os alunos do CIEP eram mais pobres, ainda que apresentassem histórico escolar - número de séries já repetidas semelhante. Os resultados apontaram que os alunos do CIEP revelavam domínio superior significativo na habilidade da fala em relação aos alunos da outra escola e desempenho homogêneo nas três habilidades, embora fosse baixo, pois nenhum índice ultrapassou $65,6 \%$. Os da escola tradicional mostraram grande oscilação nas três habilidades, com índice pouco maior na habilidade escrita que o do CIEP, porém não significativo. A análise da freqüência dos temas escolhidos pelos alunos das duas escolas sugeriu que existiam diferenças entre eles no campo ideológico.

Na pesquisa realizada em 1992, Leonardos submete as redações argumentativas dos alunos à análise de conteúdo, confirmando que os alunos do CIEP apresentavam maior capacidade de pensamento crítico em sua dimensão ideológica. 0 estudo concluiu que a postura dos alunos do CIEP foi considerada não-repetidora do senso comum, enquanto o discurso dos alunos da escola convencional enquadrava-se mais na repetição da palavra autorizada. De acordo com a autora, não há como negar o impacto dos programas educacionais - progressista ou 


\section{Horário do professor}

O segundo aspecto positivo enfocou o horário integral do professor que, segundo Paro et al. (1988 b) e Brandão (1989), permitia intervalos para planejamento, preparação de material didático e aperfeiçoamento profissional, indispensáveis diante do baixo padrão de qualidade do professor, resultante do desprestígio da profissão e dos baixos salários. Arroyo (1988) e Costa (1995) abordaram outro aspecto, considerando que o horário mais extenso do professor contribui para seu maior envolvimento com o projeto da escola, consolidando um sistema de ensino mais definido, com um corpo profissional que poderia constituir-se em interlocutor para a classe trabalhadora.

\section{Debate sobre escola pública}

O último aspecto compartilhado por vários autores foi a discussão sobre a escola pública suscitada pela proposta dos CIEPs. 0 debate contribuiu para o avanço do processo de democratização da escola pública, tanto que, nas campanhas eleitorais, apesar de ressalvas, figurou como plataforma política (Mignot, 1988) de todos os candidatos ao governo do Estado. Para Brandão (1989), CIEP tornou-se "nome próprio" para escola de tempo integral; entrou na vida dos usuários, nos debates de educação, dos intelectuais e dos políticos. Para Oliveira (1991), a discussão sobre a inadequação da escola pública decorrente da introdução do projeto teve como conseqüência a incorporação do direito à educação de boa qualidade, em jornada ampliada, às reivindicações das classes trabalhadoras na Constituição do Estado e na Lei Orgânica do Município do Rio de Janeiro. Garcia (1992) resume tudo dizendo que o CIEP colocou a discussão sobre a escola na rua.

\section{Os usuários}

Foi desenvolvida pesquisa de campo com a finalidade de identificar a representação social que professores, funcionários, alunos e seus pais tinham da escola de horário integral que freqüentavam. Por meio da representação social, seria possível dimensionar a demanda subjetiva potencial por esta escola. A representação social constitui uma forma de conhecimento, um saber prático que se refere exatamente à experiência a partir da qual ele se produz, e que serve para agir sobre o mundo (Jodelet, 1989). Para Alves-Mazzotti (1994), as interações sociais vão criando consensos que constituem verdadeiras "teorias" do senso comum. As representações sociais são estudadas, de um lado, como algo constituído. Para caracterizá-las, procurou-se observar: a atitude, as informações e o campo de representação do objeto. Por outro, estudam-se os processos formadores da representação social, chamados por Moscovici de objetivação e de ancoragem (Alves-Mazzotti, 1994).

A pesquisa se desenvolveu em quatro escolas de horário integral de primeiro segmento do Ensino Fundamental no Rio de Janeiro, duas sob administração municipal e duas, estadual. Para a seleção das escolas, foram seguidas diretrizes comuns: as quatro eram CIEPs, com marca de horário integral impressa nos prédios; foram priorizados indicadores de bom desempenho; as escolas estavam localizadas em áreas populares de periferia, com grande densidade urbana. Foram feitas $30 \mathrm{vi-}$ sitas às escolas e aplicados 568 questionários (312 alunos, 60 pais, 142 professores e 54 funcionários), no $2^{\circ}$ semestre de 2000.

Para identificar os elementos constitutivos do núcleo central da representação social, foi pedido aos professores que fizessem uma associação livre de idéias a respeito de cinco temas: escola pública; escola pública de horário integral; CIEP; Brizolão; escola para pobre. Posteriormente, foi pedido aos professores que fizessem uma hierarquização semântica, priorizando cinco atributos para cada tema, a partir do repertório levantado com as associações livres.

Tabulado o resultado, foram feitos dois conjuntos idênticos de dezessete afirmativas para que alunos, pais, professores e funcionários atribuíssem falso ou verdadeiro a cinco afirmativas para a escola de horário integral ideal e cinco, para a escola de horário integral que freqüentavam. 0 confronto entre ideal/real e falso/verdadeiro permitiu configurar as representações sociais construídas. Seus traços ganharam nitidez ao serem expostos aos resultados dos questionários (sim/não) a respeito dos motivos que levam à procura ou abandono da escola pública de horário integral.

O que ressaltou no confronto de pontos de vista foi o enfoque oposto de pais e alunos, de um lado, e professores e funcionários, de outro. Se categorizarmos as respostas dadas à demanda pela escola de horário integral pelos verbos preferir (implica comparação), gostar, 
convir (implica praticidade) e precisar (uma gradação da opção à falta de opção), veremos que pais e alunos que usufruem os serviços da escola procuram o horário integral por preferir e gostar, prioritariamente no caso dos pais e exclusivamente no caso dos alunos. 0 que eles preferem - estudar mais - é que a escola cumpra a sua função com qualidade - bons professores - e que eles gostem - mãe e aluno - do serviço prestado.

Os pais não desconhecem a necessidade - não deixar a criança na rua e precisar trabalhar -, mas colocam-na num patamar inferior. As crianças ainda não se preocupam com a necessidade. Reforçando a interpretação de que é o gostar que leva ao horário integral, os fatores relacionados como não-significativos para a demanda do horário integral excluíram o verbo necessitar. Os aspectos de conveniência - "ficar sem criança" e "irmão estudar nesta escola" - e de falta de opção - "só há vaga aî" - foram considerados sem relevância. Tanto alunos quanto pais não elegeram qualquer razão para abandonar o horário integral. Ao relacionarem os motivos que não levam ao abandono, colocaram, em visão comum, o fato de ser escola para pobre, ou seja, esse atributo não diminui ou muda a função da escola, que continua sendo necessária; num segundo plano, pais e alunos apontaram que a necessidade - "precisar trabalhar" ou "ajudar em casa" - não é suficiente para fazê-los abandonar a escola.

Ambos reconheceram que criança tem que estudar, que o fato de não gostar não leva ao afastamento da escola. Os alunos ainda vão mais longe, afirmando que mesmo se a escola tiver aspectos negativos - excesso de reprovação, falta de professor ou dificuldade na relação professor/aluno - eles não são pretexto para a saída da escola de horário integral. Em síntese, o discurso dos pais e dos alunos, além de gostar e preferir, deixou claro o reconhecimento da função e da necessidade da escola e, implicitamente, que há diferentes padrões de qualidade entre as escolas.

Professores e funcionários, com ponto de vista do servidor, construíram um discurso, em primeiro plano, comum aos dois, de necessidade - "criança não ficar na rua" e "mãe precisar trabalhar" - e, num segundo plano, de conveniência - "irmão já estuda aí" e "escola é mais próxima". A necessidade que leva ao horário integral também afasta dessa escola fatores apontados com ênfase pelos professores - "aluno precisa trabalhar" ou "ajudar em casa” - e, secundariamente, pelos funcionários. Os funcionários tiveram em comum com

\section{Fez-se notar a diferenca entre escola para pobre, que a princípio não suscita rejeição ou constrangimento, e escola pobre, relegada, descuidada, suja, baguncada, pichada, que é até freqüentada por marginal.}

pais e alunos a idéia de que escola para pobre não deixa de ser escola.

Destaca-se, do ponto de vista de professores e funcionários, que a escola de horário integral só se justifica como necessidade e conveniência. 0 fato de não reconhecerem o gostar e o preferir como motivação para esta escola desqualifica o usuário, como se ele fosse objeto exclusivo de necessidade, portanto, desprovido de atributos que caracterizam o ser humano. Indiretamente, desqualificam o próprio trabalho, porque, se atendem apenas a necessidade, não podem ter reconhecimento de qualidade, não podem ser preferidos, queixa tão presente no discurso dos professores: "não reconhecem nosso trabalho", "não vêm à reunião".

Sintetizando, a representação dos professores, corporificada na palavra Brizolão, tem no seu núcleo a idéia de escola para pobre e depósito de criança, e está associada à noção de descaso, assistencialismo e qualidade ruim. A representação social dos pais, partilhada pelos alunos, está centrada na satisfação/prazer, sem desprezar a necessidade; tem como núcleo a idéia de lazer que se relaciona com futuro e educação; a função da escola - estudar - e seu instrumento - bom professor - estão contemplados.

\section{Demanda pela escola pública de horário integral}

\section{Necessidade $x$ satisfação}

Nem todas as questões levantadas pela literatura foram iluminadas pelas representações colhidas no campo. No entanto, as diferentes óticas sobre a função social da escola de horário integral e sobre os fatores que mobilizam para a demanda dessa escola, por parte dos pais e dos professores, trouxe contribuição relevante para a discussão dessa escola, que, segundo a Lei 9394/96, é meta a ser alcançada. 


\section{Necessidade}

O discurso salvacionista de Leonel Brizola a respeito do CIEP, que passou a ser conhecido como Brizolão, suscitou a idéia de escola de marginal. Nas quatro escolas estudadas, o estigma de escola para pobre não foi considerado fator de rejeição por pais, alunos e funcionários. Não se fez associação entre concepção de educação integral e a noção da pobreza como problema social a ser segregada, função levantada na literatura para instituições totais. Assim, o CIEP não desempenhou o papel de salvaguardar a sociedade da pobreza, como também não ficou reconhecida a função de ser uma escola para salvar as crianças carentes da marginalidade. Concluiu-se que ou esta escola não é considerada de pobre ou o fato de ser assim considerada não interfere na demanda por ela. A totalidade dos pais pesquisados e cerca de $90 \%$ de alunos e funcionários das quatro escolas responderam que ser uma escola para pobre não conduz ao abandono do horário integral.

A associação entre depósito de criança e Brizolão foi feita exclusivamente por professores nas várias escolas e também no fórum pesquisado. Pelo ponto de vista dos alunos, Brizolão adquiriu um significado bastante diferente. A concepção de escola que construíram foi que ela devia ser organizada, em primeiro plano, e ter lazer, em segundo. Ao analisarem as escolas que freqüentam, os alunos das quatro escolas disseram que ela promovia educação, em primeiro plano, e que tinha lazer, em segundo. Está descrita a escola deles, mas eles dão nome a ela: num mesmo patamar, dizem que é Brizolão e que é CIEP. Assim, para os alunos, não há distinção entre CIEP e Brizolão; além disso, ambos estão associados a lazer.

Fez-se notar a diferença entre escola para pobre, que a princípio não suscita rejeição ou constrangimento, e escola pobre, relegada, descuidada, suja, bagunçada, pichada, que é até freqüentada por marginal. Essa é a escola rejeitada, que, na associação de idéias, é a escola da carência, da comida, do descaso, do descrédito, da discriminação, da desvalorização, do estigma, do fracasso, do paternalismo, da qualidade ruim. Essa escola os professores chamam de Brizolão, mas também reconhecem esses atributos na escola pública comum. Os pais percebem diferentes graus de qualidade nas escolas, mas não denominam, como os professores, as consideradas ruins de Brizolão ou escola para pobre. Os quatro grupos pesquisados afirmaram, com índices altos, que a escola que vivenciam não é uma bagunça. As mães se informam, observam, tomam conta. Os alunos não estão lá por acaso.

\section{Satisfação}

O segundo aspecto significativo para a demanda pela escola de horário integral é a satisfação dos pais, mencionada por vários autores citados. Essa avaliação positiva que os pais têm da função social desempenhada pela escola pública de horário integral confirmou-se. Os pais concebem a escola como uma instituição que prepara o futuro e, para isso, deve ter lazer e ser organizada. A escola freqüentada pelo filho preenche essa função, tornando-a uma necessidade: oferece lazer ainda que aquém do desejável; não é uma bagunça; e, além de suas expectativas, tem participação. A visão dos pais é construída a partir de vários fatores, entre os quais a satisfação dos filhos. As crianças tinham expectativa de que a escola tivesse lazer e os pais registram que essa expectativa é atendida.

Os argumentos usados pelos pais para explicar por que seus filhos estudam nessa escola priorizaram o gostar em detrimento da necessidade. Quando destacam, em primeiro plano, a avaliação subjetiva - a mãe e o aluno gostam -, os pais atribuem a si o papel de sujeitos, com direito a opção, e não meros objetos da necessidade. Também reconhecem nos filhos, apesar de serem crianças, o papel de sujeitos com capacidade de avaliação e de escolha. 0 terceiro argumento - os professores são bons -, além de manter a capacidade de avaliar, outorga a eles o julgamento do que simboliza, por excelência, a qualidade da escola - o desempenho do professor.

Só num segundo patamar os pais vão se preocupar com os aspectos materiais: a segurança da criança, seu bem-estar físico, deixando evidenciar sua responsabilidade como pais. Essa responsabilidade permanece quando enfocam a finalidade da escola - estudar mais - mesmo antes de chegar ao último argumento: a criança vai para a escola de horário integral porque a mãe precisa trabalhar. Finalmente, a satisfação dos pais também é contemplada quando não conseguem consolidar qualquer argumento que justifique a saída da escola de horário integral, nem mesmo a necessidade. Perguntados diretamente se tirariam seus filhos dessa escola, a resposta negativa ficou num patamar de $90 \%$ nas escolas estaduais e $70 \%$ nas escolas municipais. 


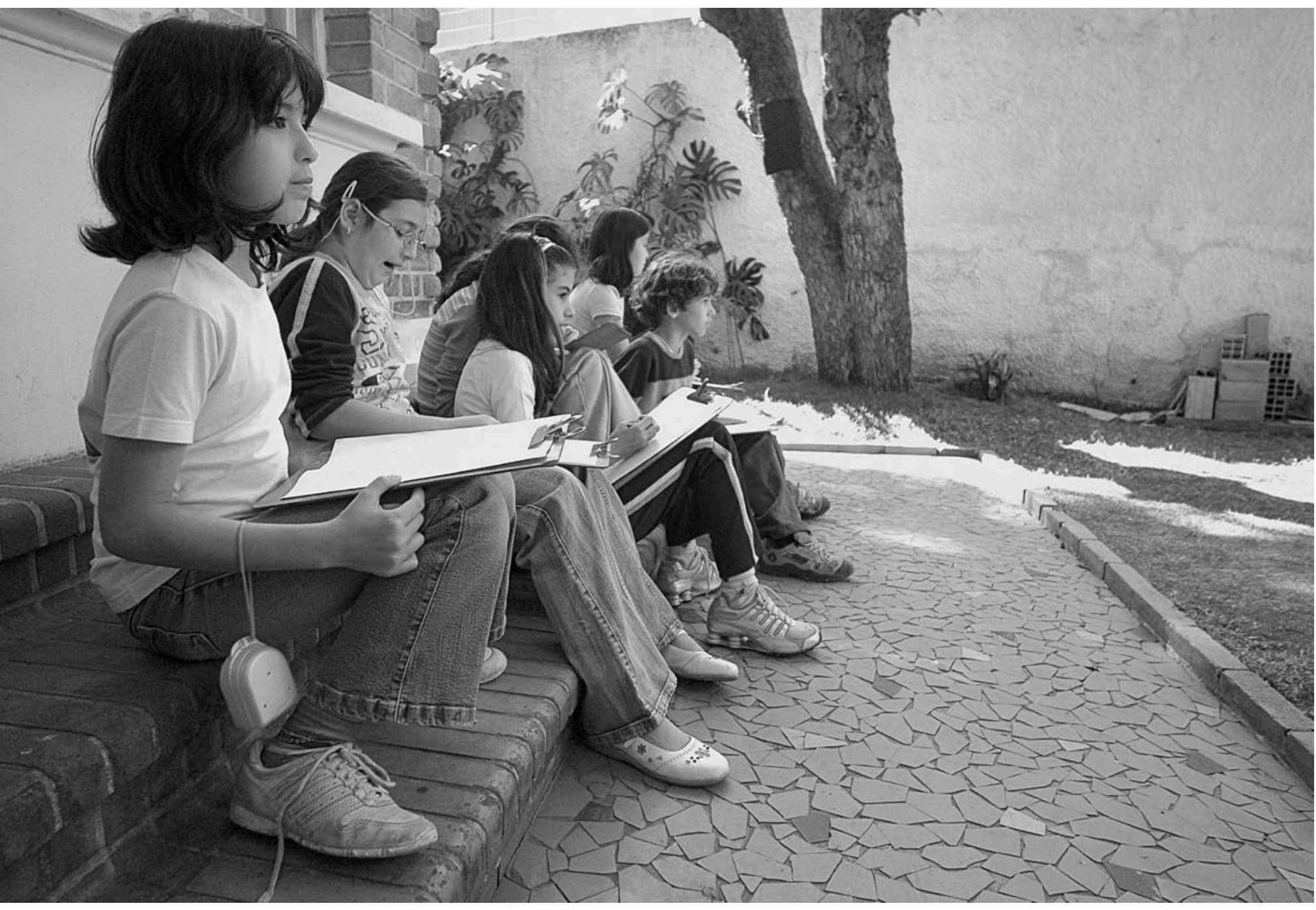

Equipe central e equipe da escola

Uma terceira temática foi tangenciada por alguns autores. A dissertação de Lima (1988) apontou o abismo entre o que a equipe central pensava da carência da criança popular e a carência real, e a incapacidade de a equipe da escola propor adaptações à proposta do PEE para atender a essa criança, redundando em contradição entre o discurso e a prática dos professores. 0 entendimento do professor de necessidade/carência, oposto ao do pai de satisfação/prazer, a respeito da motivação para o horário integral, mostra que professor e pai têm compreensões conflitantes de como vive, como se comporta, o que pensa o segmento social do qual o aluno faz parte.

As visões detectadas no decorrer desta pesquisa levaram a supor que o abismo não está entre os formuladores da proposta e os beneficiários dela. Parece estar entre os formuladores (equipe central) e os executores (professores) na escola, de um lado, e os beneficiários (pais e alunos), de outro. Ou seja, formuladores, professores e, inclusive, analistas da escola de horário integral têm visão comum a respeito das necessidades do aluno que busca esta escola em oposição àquela dos pais.

Os professores das quatro escolas e os do Fórum só reconhecem no aluno necessidade, carência, falta. 0 aluno vai para a escola de horário integral porque a mãe trabalha, porque ela não tem alternativa. Assim, a escola é reduzida à última hipótese, à falta de opção. Num segundo patamar, o aluno vai para a escola de horário integral para não ficar na rua, exposto a todos os males que podem transformá-lo num marginal. Essa concepção implica o reconhecimento da escola como um depósito, onde a criança fica guardada enquanto a mãe vai trabalhar, para suprir a carência de necessidades objetivas e primárias. Assim, o professor, de um lado, afirma que a escola não deve ser um depósito de crianças, 


\section{[...] dois temas inter- relacionados: a integração da escola à comunidade e o reconhecimento de que existe uma cultura local que é condição para que o processo de educação se desenvolva.}

que chama de Brizolão; de outro, atribui a ela a função de depósito de crianças. Além disso, dos quatro grupos, o professor foi o único a afirmar que o aluno abandona a escola porque precisa trabalhar ou porque precisa ajudar em casa para os pais poderem trabalhar, indicando mais uma vez o aluno como objeto da determinação da necessidade/carência.

Os pais priorizam a escolha, eles preferem ou gostam, mostram que os motivos que os levam a colocar seus filhos na escola de horário integral é a opção fruto de uma avaliação feita por alguém capaz disso, um sujeito, e não um objeto de carências. Os pais, quando não consolidam qualquer motivo para o abandono da escola de horário integral, desfazem a compreensão da falta de pertinência do horário integral escolar tendo em vista a necessidade da criança colaborar com a renda familiar (Paro et al., 1988 a; Cunha, 1991; Mignot, 1988) e corroboram os resultados da pesquisa de Perissé (1994): a evasão se dá pelo não cumprimento da proposta para a escola de horário integral.

Alguns autores citados deram pistas a respeito dessas leituras tão destoantes. Leonardos (1991b) afirmou que a manutenção das características básicas deste programa estaria ameaçada num momento de falta de apoio político e financeiro, pois a proposta do CIEP fora feita para a comunidade; não com a comunidade do aluno de baixa renda. Essa percepção tem por base a mesma compreensão de que a comunidade não é capaz de projetar para si mesma uma escola dessa qualidade. Passados dez anos, o projeto só se sustentou em escolas onde a liderança do diretor e a coesão da equipe foram capazes de estabelecer vínculos com a comunidade ou com a administração que permitissem a continuidade, não do projeto como um todo, mas do horário integral. Guimarães (1992) indicou que os professores não conseguiam incorporar, à sua prática, procedimentos mais coerentes com uma visão transformadora, por causa de preconcei- to de classe e de desconhecimento das causas sociais do fracasso escolar.

A relação entre classe social e diferentes interpretações das funções a serem desempenhadas pela escola já havia sido apontada por alguns autores. Coelho (1996) afirmava que a qualidade emancipatória a ser desenvolvida no ensino público fundamental seria fruto da produção de conhecimentos resultante do conflito de diferentes culturas (a do aluno e a do professor) e que o tempo de permanência do professor no ambiente escolar era indispensável para que esse processo pudesse deslanchar.

Sintetizando, a pesquisa realizada nessas quatro escolas situadas em regiões carentes levou ao reconhecimento de duas representações sociais diversas, e mesmo antagônicas, da escola pública de horário integral.

A primeira, centrada na necessidade/carência do aluno para justificar a existência desta escola, é partilhada por professores, tanto das escolas quanto do Fórum, e coincide com a análise de autores que escreveram a respeito dos CIEPs. Essa representação, corporificada na palavra Brizolão, tem no seu núcleo a idéia de escola para pobre e depósito de crianças e está associada à noção de descaso, assistencialismo e qualidade ruim.

A representação dos pais, partilhada pelos alunos, está centrada na satisfação/prazer, sem desprezar a necessidade. Tem como núcleo a idéia de lazer que se relaciona com futuro e educação. A função da escola - estudar - e seu instrumento - bom professor - estão contemplados.

A constatação dessas representações diferentes a respeito da escola, da expectativa que se tem dela e, portanto, das atribuições que deve atender, naturalmente fruto de culturas diferentes, oriundas, entre outros fatores, de posicionamento de classe diferenciados, traz à discussão dois temas inter-relacionados: a integração da escola à comunidade e o reconhecimento de que existe uma cultura local que é condição para que o processo de educação se desenvolva.

Assim, para a aproximação entre as duas concepções de função de escola delineadas neste trabalho - a de local de convivência e a de utilidade econômico-social - faz-se necessário desenvolver a interação entre escola e comunidade, instâncias de participação e decisão dos pais, e todos os espaços cotidianos que favoreçam a inclusão da expectativa dos pais no projeto pedagógico da escola. 


\section{Da Escola-Parque aos Centros Integrados de Educação Pública}

Os Centros Integrados de Educação Pública (CIEPs), projetados por Oscar Niemeyer, foram construídos e implantados no Estado do Rio de Janeiro nas duas gestões do governador Leonel Brizola, por meio do Programa Especial de Educação (I PEE, de 1983 a 1986, e II PEE, de 1991 a 1994). O Programa tinha como objetivo implantar educação pública em tempo integral para o ensino fundamental em 500 unidades escolares, que atenderia a um quinto do conjunto de alunos do estado.

Esse projeto baseou-se no diagnóstico feito por Darcy Ribeiro (1986) de que a incapacidade brasileira para educar sua população ou alimentá-la devia-se ao caráter de nossa sociedade, enferma de desigualdade e de descaso por sua população. Com essa preocupação, propôs uma escola de horário integral, como a oferecida nos países desenvolvidos, que pudesse evitar que a criança proveniente de famílias de baixa renda fosse condenada ao abandono das ruas ou à falta de assistência em lares em que são chamadas a assumir funções de adulto para que os pais possam trabalhar, tendo sua infância suprimida.

A concepção pedagógica dos CIEPs buscava assegurar a cada criança de $1^{\underline{a}}$ a $4^{\underline{a}}$ série um bom domínio da escrita, da leitura e do cálculo, instrumentos fundamentais sem os quais não se pode atuar eficazmente na sociedade letrada. De posse deles, a criança tanto poderia prosseguir seus estudos escolares como aprender por si mesma, livre, por esse aspecto, da condenação à exclusão social e habilitada ao exercício da cidadania. Outro princípio orientador era o respeito ao universo cultural do aluno no processo de introdução da criança no domínio do código culto. A escola devia servir de ponte entre a cultura do aluno, que sabe fazer muitas coisas para garantir sua sobrevivência, e o conhecimento formal exigido pela sociedade.

Essa escola foi projetada para atender 600 crianças em turno único, além de 400 à noite, na educação juvenil. Durante o dia, os alunos deveriam ter, além das aulas curriculares, orientação no estudo dirigido, atividades esportivas e recreativas, acesso à leitura de livros e revistas na biblioteca, de vídeos na sala para esse fim e participação em eventos culturais.

Como o projeto previa atendimento aos alunos provenientes de segmentos sociais de baixa renda, as escolas foram localizadas preferencialmente onde havia maior incidência de população carente. A assistência médico-odontológica, a alimentação e os hábitos de higiene eram desenvolvidos como condição para o atendimento em horário integral dos alunos deste segmento social.

Para o projeto dos CIEPs, foram significativas as experiências desenvolvidas, a partir do início dos anos de 1950, no Rio de Janeiro, antigo Distrito Federal, em cinco escolas públicas de $1^{\underline{a} a}$ a $4^{\underline{a}}$ série. Sob coordenação do Instituto Nacional de Estudos Pedagógicos (INEP), presidido na época por Anísio Teixeira, esse projeto experimental constituiu campo de pesquisa aplicada segundo orientações curriculares diversas. Mas a fundamentação do projeto de educação integral nos CIEPs, de fato, origina-se nos mesmos argumentos que levaram Anísio Teixeira, com quem Darcy Ribeiro trabalhou longos anos, a inaugurar, em 1950, o Centro Educacional Carneiro Ribeiro, em Salvador, quando era secretário de educação do Estado da Bahia.

O centro, chamado de Escola-Parque, contava com quatro escolas-classe, de nível primário, com funcionamento em dois turnos, projetadas para mil alunos cada, e uma escola-parque, com sete paviIhões, destinados às chamadas práticas educativas, freqüentadas pelos alunos em horário diverso ao da escola-classe, de forma que as crianças permanecessem o dia completo em ambiente educativo. A proposta era que esse conjunto funcionasse como centro de demonstração para a instalação de outros semelhantes no futuro.

\section{O projeto dos CIEPs no contexto da redemocratização do país}

Os governos estaduais empossados em março de 1983 tiveram seus programas influenciados pelos debates que se travaram nos anos de 1978 a 1982 . Todos os partidos, recém-criados, tentavam consolidar sua linha política em diversas áreas, e também na de educação. Leonel Brizola, eleito governador do Estado do Rio de Janeiro, nomeou Darcy Ribeiro para presidir a Comissão Coordenadora de Educação e Cultura. Em 1984, foi publicado o orçamento para a construção dos Centros Integrados de Educação Pública. Em maio de 1985, o primeiro CIEP foi inaugurado, recebendo o nome de Tancredo Neves, presidente 
da República recém-falecido. Outrašmaugurações colocaram os CIEPs no centro da campanha para prefeito do Rio de Janeiro. A vitória do PDT possibilitou a continuidade da política em vigor, apesar da intensa campanha contrária efetivada pela mídia.

Em 1986, a campanha para governador e para a Assembléia Nacional Constituinte começou com o Plano Cruzado. Novamente, o CIEP esteve presente, tanto no debate dos candidatos quanto na imprensa ou na greve dos professores da rede pública. Os CIEPs foram lidos como plataforma política para a iminente candidatura de Leonel Brizola à presidência da República. O PMDB venceu a eleição para governador em 22 estados, inclusive no Rio de Janeiro, onde Darcy Ribeiro, idealizador dos CIEPs, perdeu.

Em 1987, Moreira Franco, eleito governador no Rio de Janeiro, inviabilizou as escolas de horário integral com a descontinuidade da verba para alimentação e a redução do quantitativo de professores. Vários prédios de CIEPs foram utilizados para outras finalidades, inclusive para acolher desabrigados das enchentes. No município do Rio de Janeiro, a mudança de partido do prefeito, que deixou o PDT, levou a uma reorientação da política educacional, fazendo com que o horário integral deixasse de ser política de governo.

Em 1991, Darcy Ribeiro foi eleito para o Senado e Leonel Brizola, para o segundo mandato de governador, pelo PDT. A partir de então, uma Secretaria Extraordinária foi criada pelo governo do estado do Rio de Janeiro, para que os CIEPs antigos fossem recuperados e novos fossem implantados; todos foram equipados e lotados com profissionais, de forma que pudessem oferecer horário integral com todos os requisitos que uma escola como essa requer.

Em 1994, a meta de 500 CIEPs foi atingida, ampliando significativamente a oferta de matrículas em horário integral. Ainda nesse ano, além de ter sido realizado o primeiro concurso do Estado para selecionar professores em regime de 40 horas, para trabalharem nos CIEPs, foi implantado, em prédios de CIEPs adaptados para esta finalidade, no Município do Rio de Janeiro, o projeto experimental chamado Ginásio Público, com currículo integrando os programas de $5^{\text {a }}$ a $8^{\text {a }}$ série do Ensino Fundamental com os do Ensino Médio, em seis anos, com opção entre horário integral ou parcial.

\section{Referências Bibliográficas}

AGUIAR, Maria de Fátima. Inovações metodológicas: seus caminhos e descaminhos. Dissertação de mestrado. Faculdade de Educação da Universidade do Estado do Rio de Janeiro, 1991.

ALVES-MAZZOTTI, Alda Judith. Representações sociais: aspectos teóricos e aplicações à educação. Em Aberto, v. 14, n. 61, 1994, p.60-78.

ARROYO, Miguel Gonzales. O direito ao tempo de escola. Cadernos de Pesquisa, n. 65,1988 , p. 3-10.

BRANDÃO, Zaia. A escola de 10 grau em tempo integral: as lições da prática. Educação e Sociedade, n. 32, 1989, p. 116-129.

CAVALIERI, Ana Maria. A escola de educação integral: em direção a uma educação escolar multidimensional. Tese de doutorado. Faculdade de Educação da Universidade Federal do Rio de Janeiro, 1996.

COELHO, Ligia Martha C. Costa. Escola pública de horário integral e qualidade de ensino. Ensaio, v.11, n. 4, 1996, p. 121-128.

COSTA, Marly Abreu. Comparação das estimativas do custo/aluno em dois CIEPs e duas escolas convencionais no Município do Rio de Janeiro. Educação e Sociedade, n. 40, 1991, p. 486-501.

CUNHA, Luiz Antônio. Estado, educação e democracia no Brasil. 2. ed. São Paulo: Cortez / EDUFF / FLACSO, 1991.

GARCIA, Regina. CIEP - a paixão deslocada. Proposta n. 52. Rio de Janeiro: FASE. 1992, p. 11-13.

GUIMARÃES, Miriam Reis. A escola de horário integral: um projeto de escola crítica em construção. Dissertação de mestrado. Faculdade de Educação da Universidade do Estado do Rio de Janeiro, 1992.

JODELET, Denise. Représentations sociales: un domaine en expansion. In: JODELET, D. (org.) Les représentations sociales. 2. ed. Paris: Presses Universitaires de France, 1989.

LEAL, Maria Cristina. Práticas clientelísticas e recursos públicos para a educação de primeiro e segundo graus. Tese de doutorado. Faculdade de Educação da Universidade Federal do Rio de Janeiro, 1991.

LEONARDOS, Ana Cristina. Opportunities to learn academic skills in the Brazilian public schools: a comparative case study. Tese de doutorado. Stanford University, 1990.

. Avaliação do desempenho de alunos de CIEP e de escola convencional: comparando o desenvolvimento de pensamento crítico. Relatório de Pesquisa. Rio de Janeiro: CAPES/UFRJ, 1991b.

. Análise de discurso das produções acadêmicas de alunos de CIEP (representativo da proposta original) e de escola convencional. Relatório de Pesquisa. Rio de Janeiro: CAPES/UFRJ, 1992.

LIMA, Valdileia. CIEPs: a re-invenção da escola pública? Dissertação de mestrado. Faculdade de Educação da Universidade Federal Fluminense, 1988.

, (1988). CIEPs : a impotência de um desejo pedagógico. Dissertação de mestrado. Faculdade de Educação da Universidade Federal Fluminense.

MAURÍCIO, Lúcia V.; SILVA, Isabel. Avaliação externa 1993 e 1994. Carta 15: O novo livro dos CIEPs. Brasília: Senado Federal, 1995, p. 193-219.

MIGNOT, Ana Christina. CIEP: alternativa para a qualidade de ensino ou nova investida do populismo em educação? Dissertação de mestrado. Faculdade de Educação da Pontifícia Universidade Católica do Rio de Janeiro, 1988.

MOUSSATCHÉ, Helena. A arquitetura escolar como representação social da escola. Tese de doutorado. Faculdade de Educação, UFRJ, 1998.

OLIVEIRA, Carlos Alberto, (1991). CIEP: modelos subjacentes de uma escola que está fazendo escola. Dissertação de mestrado. Faculdade de Educação da Universidade Federal do Rio de Janeiro.

PARO, Vítor et al.. A escola pública de tempo integral: universalização do ensino e problemas sociais. Cadernos de Pesquisa, n. 65, p. 11-20, 1988a.

. Viabilidade da escola pública em tempo integral. Educação e Sociedade, n. 29, 1988b, p. 86-99.

. Escola de tempo integral: desafio para o ensino público. São Paulo: Cortez, 1988c.

PERISSÉ, Vanda Lúcia S.. Análise da evasão de alunos de um CIEP de segundo segmento do primeiro grau para escolas de horário parcial. Dissertação de mestrado. Faculdade de Educação da Universidade Federal do Rio de Janeiro, 1994.

RIBEIRO, Darcy. O livro dos CIEPS. Rio de Janeiro: Bloch, 1986.

. Balanço crítico de uma experiência educacional. In: RIBEIRO, Darcy. Carta 15: O novo livro dos CIEPs. Brasília: Senado Federal, 1995. p. 17-24. 